\title{
Characterization of Low and Intermediate Molecular Weight Hydrogen Silsesquioxanes by Mass Spectrometry
}

\author{
Huiping Chen and Ron E. Tecklenburg \\ Analytical Sciences Department, Dow Corning Corporation, Midland, Michigan, USA
}

\begin{abstract}
Hydrogen silsesquioxanes (HSQ or H-resin), represented by $\left(\mathrm{HSiO}_{3 / 2}\right)_{2 n}$ or $\mathrm{T}_{2 n}^{\mathrm{H}}$ are an important class of polymers that have gained popularity as spin-on dielectrics by the electronic industry. Previously in the literature, small oligomeric species such as $\left(\mathrm{HSiO}_{3 / 2}\right)_{2 n}$, where $n=$ 4-16, have been identified by GC-MS. However, nondestructive mass spectral results for larger H-resin molecules have not been reported, likely due to the nonpolar nature of these molecules. We have utilized a number of "soft" ionization techniques such as field desorption (FD), desorption chemical ionization (DCI), and matrix-assisted laser desorption/ionization (MALDI), and demonstrated that they are amenable to hydrogen silsesquioxanes. The $\left[\mathrm{T}^{\mathrm{H}}{ }_{2 \mathrm{n}}-\right.$ $\mathrm{H}]^{+\cdot}$ ions were observed by FD-MS while $\left[\mathrm{T}^{\mathrm{H}}{ }_{2 \mathrm{n}}+\mathrm{NH}_{4}\right]^{+}$and $\left[\mathrm{T}^{\mathrm{H}}{ }_{2 \mathrm{n}}+\mathrm{Na}\right]^{+}$ions were found utilizing DCI and MALDI, respectively. Based upon the MS results, the polymer compositions as well as molecular weight information can be easily obtained. The detailed structures of $\mathrm{H}$-resin components, however, remain a difficult issue, which cannot be answered by MS data alone. With these preliminary MS results, we have clearly demonstrated that mass spectrometry with the above-mentioned ionization techniques is an invaluable tool that can be utilized when attempting to solve the challenge set forth by the complexity of hydrogen silsesquioxane materials. (J Am Soc Mass Spectrom 2006, 17, 1437-1441) (c) 2006 American Society for Mass Spectrometry
\end{abstract}

$\mathrm{H}$ ydrogen silsesquioxane (H-silsesquioxane, HSQ, or H-resin), first synthesized by Collins and Frye in 1970 [1], has the general chemical composition of $\left(\mathrm{HSiO}_{3 / 2}\right)_{2 n}$ where $n>3$. It received much attention after its unique applications as carbonless protective coatings and interlayer dielectrics were successfully demonstrated in the early 1990s for the semiconductor industry [2-4]. The growing interest in H-resin is evidenced by the increasing number of studies published in the external literature, from both experimental and theoretical investigations [5-7].

Due to its unique physical and chemical properties, it is of prime importance to characterize H-resins for a fundamental understanding of their structure-property relationships. While the composition of H-resin, $\left(\mathrm{HSiO}_{3 / 2}\right)_{\mathrm{n}}$, appears simple, its molecular weight distribution and three-dimensional structures vary greatly depending upon the synthetic reaction conditions utilized, which in turn can strongly impact the physical and electronic properties of the final material. The molecular weight of hydrogen silsesquioxanes can vary from a few hundred to millions of $\mathrm{Da}$, and little is

Published online July 26, 2006

Address reprint requests to Dr. H. Chen, Analytical Sciences Department, Dow Corning Corp. 2200 W. Salzburg Rd., P.O. Box 994, Mail Stop CO41D1, Midland, MI 48686, USA. E-mail: huiping.chen@dowcorning.com known about their specific molecular structures. The structure of $\mathrm{H}$-resin is often explored using ${ }^{1} \mathrm{H}$ and ${ }^{29} \mathrm{Si}$ NMR [5]. Gel-permeation chromatography (GPC) has been the method of choice for determination of molecular weight, relative to polystyrene standards, or more accurately by utilizing triple detection. Although mass spectrometry has proven to be an invaluable tool for molecular weight determination, the mass spectrometric results for hydrogen silsesquioxanes have been scarce. The only report found in the literature describes the identification of polyhedral $\left(\mathrm{HSiO}_{3 / 2}\right)_{2 n}$ structures by Agaskar and Klemperer [5], where $n=4-16$ using gas chromatography-mass spectrometry (GC-MS). Previously, we have conducted a study to evaluate the ability of both field desorption (FD) and desorption chemical ionization (DCI) mass spectrometry, as a direct means to ionize thermally labile/intractable organosilicon polymers [8]. FD and DCI were found to be excellent ionization methods for the direct analysis of intermediate molecular weight $(1000-10,000 \mathrm{u})$ organosilicon polymers including H-resins $[9,10]$. More recently, other soft ionization techniques such as electrospray ionization (ESI) or matrix assisted laser desorption/ionization (MALDI) have been widely utilized for mass spectrometric analysis of many organofunctional silsesquioxanes [11-20], however, to the best of our knowledge, nondestructive mass spectrometric 
results of $\mathrm{H}$-resins using these soft ionization techniques have not previously been published. Herein, we include the FD and DCI mass spectrometric data, which have been presented previously [9, 10], and the first MALDI data for a low molecular weight $\mathrm{H}$-resin material.

\section{Experimental}

Two H-resins, $\mathbf{A}$ and $\mathbf{B}$, were prepared at different times from $\mathrm{HSiCl}_{3}$, using a method similar to that of Collins and Frye [1].

The field desorption (FD) mass spectra were collected using a Kratos Concept $1 \mathrm{H}$ double-focusing mass spectrometer of Nier-Johnson horizontal geometry. The FD ion source consists of a FD emitter that is attached to an electrically isolated probe, which can be biased from 0 to $-3 \mathrm{kV}$, and a set of beam centering plates used for steering the ion beam and optimizing ion current signals at the detector. A solution of H-resin, B, was prepared by dissolving the material in Fisher HPLC grade toluene, with a final concentration of ca. $0.1 \%$. The tip of the FD probe, which contains both the field emitter and an extraction electrode, was briefly dipped into the H-resin solution. The probe was then inserted into the FD ion source, and following solvent removal, $8 \mathrm{kV}$ was applied to the FD emitter. The FD emitter was resistively heated at a rate of $2.5 \mathrm{~mA} / \mathrm{min}$ until adequate detector signal was observed. A mass range of 100 to $2000 \mathrm{Da}$ with a scan rate of $5 \mathrm{~s} /$ decade and an electron multiplier gain of $1 \times 10^{6}$ was used to collect the final FD spectrum. Twenty individual mass spectra were collected and signal averaged using Kratos Mach 3, Unix-based software.

The desorption chemical ionization (DCI) mass spectra were collected using the same Kratos instrument with the DCI source operated at $220 \mathrm{eV}$ and $120^{\circ} \mathrm{C}$. A solution of H-resin $\mathbf{B}$ was prepared at a final concentration of ca. $100 \mathrm{ng} / \mathrm{ul}$ in toluene. Typically, $0.5 \mathrm{ml}$ of the H-resin solution was transferred via syringe to the tip of the DCI probe. The DCI probe tip consists of a loop of tungsten wire, which can be resistively heated at rates from 1 to $100{ }^{\circ} \mathrm{C} / \mathrm{s}$, using a Kindamen programmable power supply. The sample coated DCI probe was directly inserted into the DCI source and after solvent removal $8 \mathrm{kV}$ was applied to the DCI source. High purity ammonia gas $(99.95 \%)$, was used as the chemical ionization reagent gas in this experiment. For the $\mathrm{H}$ resin B sample, the DCI probe tip was resistively heated up to $200^{\circ} \mathrm{C}$, using a DCI probe tip heating rate of $15^{\circ} \mathrm{C} / \mathrm{s}$, until the sample ion intensity profile was observed to increase, reach a maximum and then decrease as the bulk material was distilled off the end of the DCI probe tip. A mass range of 200 to $5000 \mathrm{Da}$ with a magnet scan rate of $5 \mathrm{~s} /$ decade and an electron multiplier gain of $3 \times 10^{5}$ were used to collect the DCI mass spectrum. The DCI mass spectrum was collected with an instrument mass resolving power of $5000(10 \%$ valley definition). Ten individual DCI mass spectra were collected and signal-averaged using Kratos Mach 3, Unix-based software.

MALDI-TOF MS was carried out using a Bruker Biflex III instrument (Bruker Daltonics, Billerica, MA) equipped with a $337 \mathrm{~nm}$ nitrogen laser and operated in the linear mode with an acceleration voltage of $19 \mathrm{kV}$. The H-resin A sample was dissolved in tetrahydrofuran (THF), as was 2,5-dihydroxybenzoic acid (DHBA) matrix (Aldrich, Milwaukee, WI) doped with small amount of $\mathrm{NaCl}$ to enhance cationization. Approximately $0.5 \mathrm{ml}$ of the H-resin A solution was first placed on a Scout 386 probe with another $0.5 \mathrm{ml}$ matrix solution overlaid on top of the first deposited layer. The mass spectrum was acquired in the positive-ion mode and represents the sum of 250 individual scans. To avoid matrix interference, ions $<800 \mathrm{Da}$ were deflected off-axis, thus preventing their detection.

\section{Results and Discussion}

Previously, we have attempted to analyze H-resins using electrospray ionization (ESI) MS without much success. It usually resulted in complex mass spectra that were difficult to interpret. The $\mathrm{Si}-\mathrm{H}$ bond strength is quite low and its conversion into $\mathrm{Si}-\mathrm{X}(\mathrm{X}=\mathrm{C}, \mathrm{N}, \mathrm{O}$, or halides, etc.) can be induced under mild conditions [21]. It is also known, from experience, that the stability of HSQ materials can be greatly affected if it comes into contact with moisture, bases, or metals. Since polar protic solvents such as $\mathrm{MeOH}$ are often used in the ESI analysis of silsesquioxanes, the complex ESI mass spectra observed are likely the result of undesirable reactions occurring during sample preparation and analysis. To minimize mass spectral complexity for hydrogen silsesquioxanes, MALDI, FD, or DCI can be utilized since aprotic solvents are used to dissolve the resin which are then subsequently removed by vacuum before mass analysis. By avoiding possible side reactions, the mass spectra thus obtained should truly reflect the nature of the original material.

\section{MALDI-TOF MS}

Figure 1 shows the MALDI-TOF mass spectrum of $\mathrm{H}$-resin A. Since the sample was prepared using 2,5-dihydroxybenzoic acid (DHBA) as a matrix with the addition of $\mathrm{NaCl}$, the ions observed are exclusively $[\mathrm{M}+\mathrm{Na}]^{+}$ions. Note that all ions discussed in this paper are singly charged. Since $\mathrm{H}$-resin consists of three elements, hydrogen, silicon, and oxygen, and each silicon is bound to a hydrogen atom and three oxygen atoms (strictly speaking, an average of one and a half oxygens), the $\mathrm{Na}^{+}$ion has to bind exclusively to oxygen atoms to form a stable adduct ion. The spectrum in Figure 2 indicates the presence of $[\mathrm{M}$ $+\mathrm{Na}]^{+}$ions over a wide mass range, from 800 up to $7500 \mathrm{Da}$. Since ions below $800 \mathrm{Da}$ were deflected (see the Experimental section), to avoid matrix interferences, the first significant ion was observed at $977 \mathrm{Da}$, which corresponds to $\mathrm{T}_{18}^{\mathrm{H}}\left(\mathrm{T}^{\mathrm{H}}=\mathrm{HSiO}_{3 / 2}\right)$. The insert 


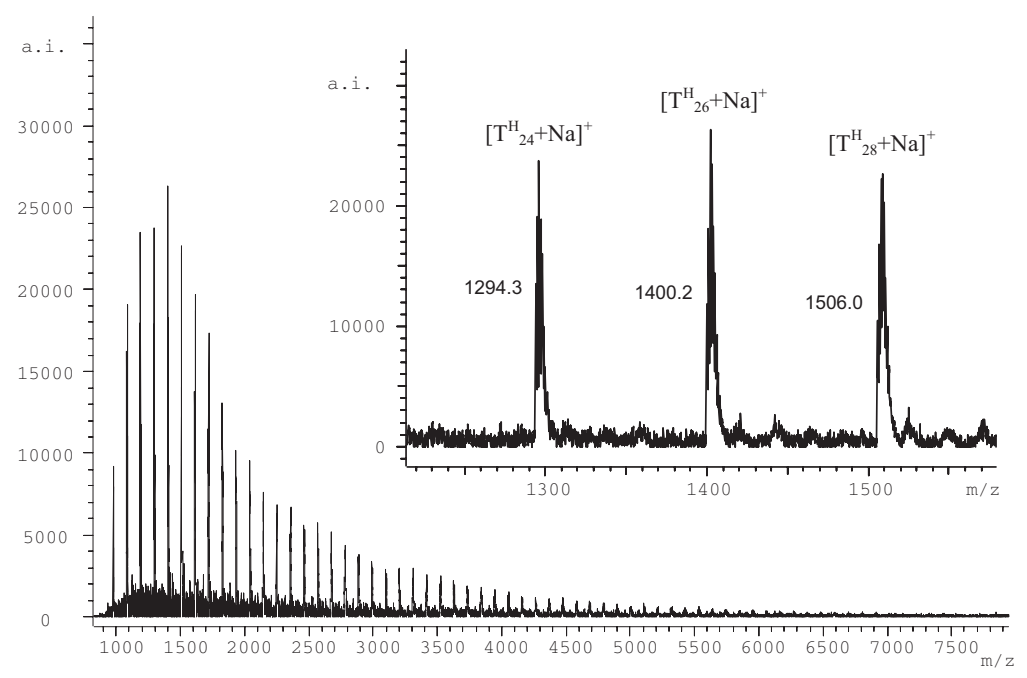

Figure 1. MALDI-TOF mass spectrum of an H-resin, A.

in Figure 1 provides a magnified view of the ions which correspond to the $\left[\mathrm{T}^{\mathrm{H}}{ }_{24}+\mathrm{Na}\right]^{+},\left[\mathrm{T}^{\mathrm{H}}{ }_{26}+\mathrm{Na}\right]^{+}$, and $\left[\mathrm{T}_{28}^{\mathrm{H}}+\mathrm{Na}\right]^{+}$ions. Note that the mass difference between adjacent peaks is $106 \mathrm{Da}$, which corresponds to twice the mass of a hydrogen silsesquioxane unit $\left(2 \mathrm{~T}^{\mathrm{H}}\right)$. Two $\mathrm{O}_{3 / 2} \mathrm{SiH}$ groups represent the smallest "building block" unit by which hydrogen silsesquioxanes assemble. This is particularly true when hydrogen silsesquioxanes are synthesized from $\mathrm{HSiCl}_{3}$ in low polarity aprotic solvents since free silanol groups rapidly condense to from completely closed ( $\mathrm{SiOH}$ free) structures. In other experiments where the deflector mass cutoff was lowered to $300, \mathrm{~T}^{\mathrm{H}}{ }_{14}$ and $\mathrm{T}_{16}^{\mathrm{H}}$ were also observed by MALDI. Even smaller polyhedral oligomers were observed by GC-MS where $\mathrm{T}_{2 n}^{\mathrm{H}}(n=4-9)$ were readily identified. Agaskar and Klemperer [5] reported previously the identification of these polyhedral H-resin species by GC-MS as well. Since the EI spectra of these species cannot be found anywhere in the literature, we have included the GC-MS chromatogram as well as the typical $70 \mathrm{eV}$ EI mass spectra of $\mathrm{T}^{\mathrm{H}}{ }_{2 \mathrm{n}}(n=4-9)$ in Supplementary Material section (which can be found in the electronic version of this article).

\section{FD-MS and DCI-MS}

Figure 2 contains the FD mass spectrum of H-resin $\mathbf{B}$. The observed field desorbed ions represent $\left[\mathrm{T}_{2 \mathrm{H}}^{\mathrm{H}}-\right.$ $\mathrm{H}]^{+\cdot}$ species where $n \geq 4$. A comparison between Figure 2 and the EI mass spectra obtained by GC-MS clearly demonstrates that FD is an inherently "soft" ionization technique. The internal energy deposited into the $\mathrm{H}$ resin molecules is minimal and, therefore, subsequent fragmentation of the molecular ions is greatly reduced. An even "softer" approach using DCI was attempted and the result is shown in Figure 3. Pseudomolecular ions $\left[\mathrm{T}^{\mathrm{H}}{ }_{2 \mathrm{n}}+\mathrm{NH}_{4}\right]^{+}$were observed up to $4000 \mathrm{Da}$. In the

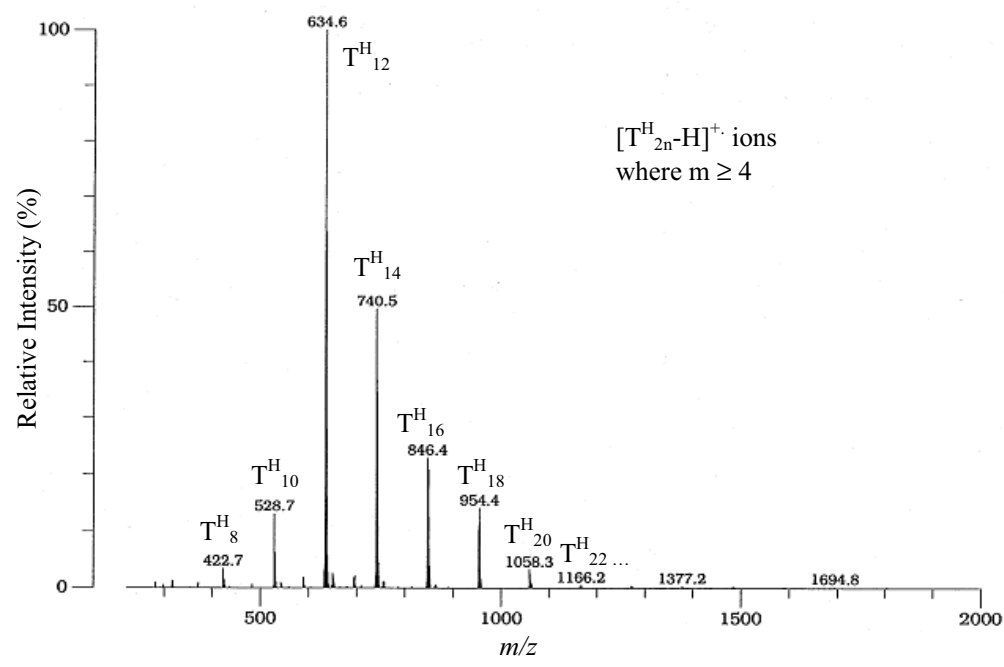

Figure 2. Field desorption mass spectrum of an H-resin, B. 


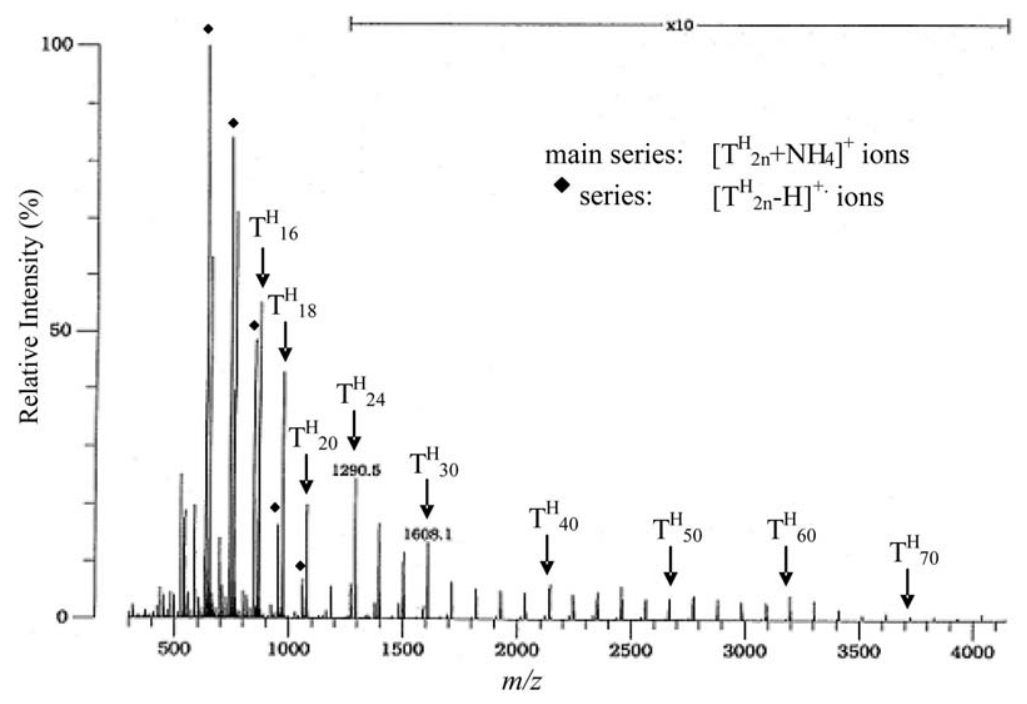

Figure 3. DCI mass spectrum of an H-resin, B.

low molecular weight region, the data indicated mixed FD and DCI mechanisms since both $\left[\mathrm{T}^{\mathrm{H}}{ }_{2 \mathrm{n}}-\mathrm{H}\right]^{+\cdot}$ and $\left[\mathrm{T}^{\mathrm{H}}{ }_{2 \mathrm{n}}+\mathrm{NH}_{4}\right]^{+}$ions were observed.

$\mathrm{H}$-resin is a unique material that only consists of three elements, $\mathrm{Si}, \mathrm{O}$, and $\mathrm{H}$. The soluble product of the Frye and Collins reaction [1] contains oligomeric species and high molecular weight components. The ${ }^{29} \mathrm{Si}$ NMR analysis of HSQ material typically yields a broad resonance between -80 and $-90 \mathrm{ppm}$ [22], which is not particularly informative other than confirming the general composition $\left(\mathrm{HSiO}_{3 / 2}\right)_{\mathrm{n}}$. We have also demonstrated that the detailed compositions of H-resin components, such as by $\mathrm{T}_{2 \mathrm{H}}^{\mathrm{H}}(n \geq 4)$ can be easily derived from MALDI-TOF MS, FD-MS, DCI-MS, and GC-MS data. As for the detailed structures of these components, it is not a simple question to address. Threedimensional silsesquioxanes generally consist of a mixture of diverse molecular weight structures, and these may include polyhedrals, ladders, tubes, partial cages, interconnected cages, or random structures. Even for small polyhedral species such as $\mathrm{T}^{\mathrm{H}}{ }_{14}$ and $\mathrm{T}^{\mathrm{H}}{ }_{16}$, a number of isomers exist as indicated by the GC-MS chromatogram. Possible structures for $\mathrm{T}^{\mathrm{H}}{ }_{2 \mathrm{n}}(n=6-9)$ have been discussed in detail by Agaskar and Klemperer, which reflected strong correlation between topological features of these polyhedral structures and their ${ }^{29} \mathrm{Si}\left[{ }^{1} \mathrm{H}\right] \mathrm{NMR}$ chemical shifts [5]. A significant amount of computational work has also been carried out by researchers on the structures of larger silsesquioxane molecules which suggests that $\mathrm{H}$-resin consists of mixtures of cage-like ends interconnected by ladder-like units [23]. The diversity of structural components present in $\mathrm{H}$-resin makes this material different from many polymers, which can be isolated as pure compounds and fully characterized. The challenge set forth by such a complex material is to identify common building blocks that can be measured, and then to connect these blocks, to ultimately provide a generic structure that is flexible enough to account for the variation of molecular weight as well as other measurable parameters. However, the task is certainly beyond the capability of an individual spectrometric technique such as NMR or MS alone. Nevertheless, the molecular weight (MW) and molecular weight distributions (MWD) of H-resin materials are important for a better understanding of their chemical and physical properties. The molecular weight information can be accurately determined by means of recalibrating GPC data using the MALDI-MS results for H-resin fractions with narrow polydispersities.

\section{Conclusions}

Resinous hydrogen silsesquioxanes (HSQ, or H-resin) have gained considerable interest as spin-on dielectrics in the integrated circuit design industry because of its low dielectric constant and other superior insulating properties. Despite its growing popularity, little mass spectrometric data can be found in the literature. Oligomeric H-resin species have been identified previously by GC-MS. In this report, we have demonstrated that soft ionization techniques such as FD, DCI, and MALDI are applicable to larger $\mathrm{H}$-resin molecules and offer direct determination of polymer compositions and molecular weight distributions. Although the detailed structures of H-resin components is a difficult question to be answered by MS data alone, the information obtained by various MS techniques hopefully sheds light onto the challenges set forth by the intrinsic complexity of H-resin materials.

\section{Acknowledgments}

The authors acknowledge Dr. Sanlin Hu for providing the Hsilsesquioxane sample. The analytical sciences department of Dow 
Corning is acknowledged for approving the publication of this report.

\section{References}

1. Frye, C. L.; Collins, W. T. Oligomeric Silsesquioxanes, $\left(\mathrm{HSiO}_{3 / 2}\right)_{\mathrm{n}}$ J. Am. Chem. Soc. 1970, 92, 5586-5588.

2. Chandra, G. Low Temperature Ceramic Coatings for Environmental Protection of Integrated Circuits. Mater. Res. Soc. Symp. Proc. 1991, 203, 97-108.

3. Weiss, K. D., Frye, C. L. 1991; Patent US4999397.

4. Bank, H. M., Ciufentes, M. E., Martin, T. E. 1991; Patent US5010159.

5. Agaskar, P. A.; Klemperer, W. G. The Higher Hydridospherosiloxanes: Synthesis and Structures of $\mathrm{H}_{\mathrm{n}} \mathrm{Si}_{\mathrm{n}} \mathrm{O}_{1.5 \mathrm{n}}(\mathrm{n}=12,14,16,18)$. Inorg. Chim. Acta 1995, 229, 334-335.

6. Xiang, K.-H.; Pandey, R.; Pernisz, U. C.; Freeman, C. Theoretical Study of Structural and Electronic Properties of H-Silsesquioxanes. J. Phys. Chem. B 1998, 102, 8704-8711.

7. Cheng, W.-D., Xiang, K.-H., Pandey, R; Pernisz, U. C. Calculations of Linear and Nonlinear Optical Properties of H-Silsesquioxanes. J. Phys. Chem. B 2000, 104, 6737-6742.

8. Prokai, L. Field Desorption Mass Spectrometry; Brame, E. G., Jr., Ed.; Marcel Dekker, Inc.: New York, 1990.

9. Tecklenburg, R. E. An Evaluation of the Desorption Chemical Ionization Mass Spectrometry of Organosilicon Polymers. Proceedings of the 40th Annual Conference of the American Society of Mass Spectrometry; Washington D.C., May 31-June 5, 1992.

10. Tecklenburg, R. E. An Investigation of the Desorption Chemical Ionization and Field Desorption Mass Spectrometry of Organosilicon Polymers. Proceedings of the American Chemical Society, Midland Division, Fall Scientific Meeting; Saginaw, Michigan, October 1992.

11. Hong, B.; Thoms, T. P. S.; Murfee, H. J.; Lebrun, M. J. Highly Branched Dendritic Macromolecules with Core Polyhedral Silsesquioxane Functionality. Inorg. Chem. 1997, 36, 6146-6165.
12. Bakhtiar, R.; Feher, F. J. Mass Spectrometric Characterization of Polyhedral Oligosilsesquioxanes and Heterosilsesquioxanes. Rapid Commun. Mass Spectrom. 1999, 13, 687-694.

13. Bakhtiar, R. Mass Spectrometric Characterization of Silsesquioxanes. Rapid Commun. Mass Spectrom. 1999, 13, 87-89.

14. Fasce, D. P.; Williams, R. J. J.; Erra-Balsells, R.; Ishikawa, Y.; Nonami, H. One-Step Synthesis of Polyhedral Silsesquioxanes Bearing Bulky Substituents: UV-MALDI-TOF and ESI-TOF Mass Spectrometry Characterization of Reaction Products. Macromolecules 2001, 34 , 3534-3539.

15. Wallace, W. E.; Guttman, C. M.; Antonucci, J. M. Molecular Structure of Silsesquioxanes Determined by Matrix-Assisted Laser Desorption/Ionization Time-of-Flight Mass Spectrometry. J. Am. Soc. Mass Spectrom. 1999, 10, 224-230.

16. Wallace, W. E.; Guttman, C. M.; Antonucci, J. M. Polymeric Silsesquioxanes: Degree-of-Intramolecular-Condensation Studies by Mass Spectrometry. Polymer 2000, 41, 2219-2226.

17. Tecklenburg, R. E.; Wallace, W. E.; Chen, H. Characterization of a $\left[\left(\mathrm{O}_{3 / 2} \mathrm{SiMe}\right)_{x}(\mathrm{OSi}(\mathrm{OH}) \mathrm{Me})_{\mathrm{y}}\left(\mathrm{OSiMe}_{2}\right)_{\mathrm{z}}\right]$ Silsesquioxane Copolymer Resin by Mass Spectrometry. Rapid Comm. Mass Spectrom. 2001, 15, $2176-2185$.

18. Bujalski, D. R.; Chen, H.; Tecklenburg, R. E.; Moyer, E. S.; Zank, G. A.; $\mathrm{Su}, \mathrm{K}$. Compositional and Structural Analysis of a $\left(\mathrm{PhSiO}_{3 / 2}\right)_{0.35}(\mathrm{Me}-$ $\left.\mathrm{SiO}_{3 / 2}\right)_{0.40}\left(\mathrm{Me}_{2} \mathrm{ViSiO}_{1 / 2}\right)_{0.25}$ Resin. Macromolecules 2003, 36, 180-197.

19. Bujalski, D. R.; Chen, H.; Zank, G. A.; Su, K. Synthesis of $\left(\mathrm{PhSiO}_{3}\right.$ 2) ${ }_{0.35}\left(\mathrm{MeSiO}_{3 / 2}\right)_{0.40}\left(\mathrm{Me}_{2} \mathrm{ViSiO}_{1 / 2}\right)_{0.25}$ Resins. Macromolecules 2003, 36, 3529-3539.

20. Farahani, M.; Wallace, W. E.; Antonucci, J. M.; Guttman, C. M. Analysis by Mass Spectrometry of the Hydrolysis/Condensation Reaction of a Trialkoxysilane in Various Dental Monomer Solutions. J. Appl. Polym. Sci. 2006, 99, 1842-1847.

21. Brook, M. A. Silicon in Organic, Organometallic, and Polymer Chemistry; John Wiley and Sons, Inc.: New York, 2000, p 171.

22. Taylor, R. B.; Parbhoo, B.; Fillmore D. M. The Analytical Chemistry of Silicones; Smith, A. L.; Ed.; John Wiley and Sons, Inc.: New York, 1991, p 347.

23. Grigoras, S., Lipp, E. D., Yue, H. Theoretical and Experimental Study of H-Resin Structure. Dow Coring Corporation internal report, unpublished. 